\title{
Effect of preparation condition on the optical properties of transparent conducting oxide based on zinc oxide
}

\author{
Mostafa Mohamed Abd El-Raheem ${ }^{1,2}$, Hoda Hamid Al-Ofi ${ }^{1}$, Abdullah Alhuthali ${ }^{1}$, \\ Ateyyah Moshrif AL-Baradi ${ }^{*}$ \\ ${ }^{1}$ Physics Department, Faculty of Science, Taif University, Taif, Saudi Arabia \\ ${ }^{2}$ Physics Department, Faculty of Science, Sohag University, Sohag, Egypt
}

Email address:

thobyani@yahoo.com (Ateyyah M. AL-Baradi), a.albaradi@tu.edu.sa (Ateyyah M. AL-Baradi)

To cite this article:

Mostafa Mohamed Abd El-Raheem, Hoda Hamid Al-Ofi, Ateyyah Moshrif AL-Baradi. Effect of Preparation Condition on the Optical

Properties of Transparent Conducting Oxide Based on Zinc Oxide. Optics. Vol. 4, No. 3, 2015, pp. 17-24. doi: 10.11648/j.optics.20150403.11

\begin{abstract}
Thin films of $\mathrm{Al}_{2} \mathrm{ZnO}_{4}$ were prepared using DC sputtering technique at room temperature. One set of the films of different thicknesses were prepared under the same condition of preparation, another one was prepared under different rate of flow of argon, the last set was prepared under different pressure of the gas. The optical energy gap, Urbach tails, refractive index of the films, single oscillator energy and dispersion energy were studied. The effect of changing the condition of preparation on the optical constants was investigated.
\end{abstract}

Keywords: Tin Film, Sputtering, Optical Gap, Refractive Index, Urbach Tails, Dispersion Energy

\section{Introduction}

It is known that transparent conductive oxide (TCO) is promising because of their wide range of applications in opto-electronic devices. Most transparent conducting oxide are based on $\mathrm{SnO}_{2}, \mathrm{In}_{2} \mathrm{O}_{3}, \mathrm{ZnO}$ and their mixed compounds are formed by different physical and chemical techniques. The properties of transparent electrodes have been improved using sputtering methods, but there methods of deposition have drawback, such as their high cost the longer fabrication time [ 1]. Transparent conducting oxide coating will support the development of the next generation of photovoltaic components [2-4]. The electrical and optical properties of transparent conducting oxide films were found to depend on composition, structure, crystallinity defect density, surface roughness and dopant concentration [5-7]. The importance of aluminum zinc oxide $\mathrm{Al}_{2} \mathrm{ZnO}_{4}$ is due to its wide band gap which gives the uniqueness property where it has been weakly studied for various practical applications such as solar cells [ 8], flat panel display [9], surface acoustic devices, optical waveguide, gas sensors micro machined actuator [10-12]. The physical properties of the films depend strongly on the condition of preparation as deposition technique, the growth methods and post deposition treatment. Aluminum zinc oxide AZO is transparent for visible light, making them promising for optical applications. AZO is regarded as a distinguished substitute for indium oxide (ITO) because zinc oxide is a nontoxic, inexpensive and abundant material [13]. A lot of attentions have been paid by industry to develop thin AZO films. Zinc oxide is an n-type II-IV semiconductor with a band gap of $3.2 \mathrm{eV}$ at room temperature [14]. Substituting a fraction of the $\mathrm{Zn}^{+2}$ ions by $\mathrm{Al}^{+3}$ ions serve as electron donors. Pure zinc oxide $\mathrm{ZnO}$ thin films lack stability due to adsorption of atmospheric oxygen, which decreases its conductivity [15]. Thus, polycrystalline $\mathrm{ZnO}$ thin films have been doped with elements from group II and III metal ions such as indium In, aluminum $\mathrm{Al}$, gallium $\mathrm{Ga}$, copper $\mathrm{Cu}$, etc. to enhance their structural, optical and electrical properties [16-19]. Therefore, doping is required to get high transparency, stability and high conductivity. Aluminum zinc oxide thin film have high transmittance in the visible region, and low resistivity, and the optical band gap can be controlled using Al doping amount [20]. The conductivity of AZO is originated from the ionization of $\mathrm{Zn}$ interstitials and oxygen vacancies, which act as donor levels. Aluminum zinc oxide thin films with high c-axis oriented crystalline structure along (002) plane can reduces the electrical resistivity due to increase in carries mobility resulting from reducing the probability of the scattering of the carriers at the grain boundary and scattering frequency. 
Also, AZO exhibit piezo electric properties, which are used in various pressure transducers, acousto-optic devices, surface and bulk acoustic wave devices. The dc magnetron sputtering process in used most often, due to its high deposition rates and process stability and reliability. Also, for preparing AZO films, ion beam sputtering process was used due to its character of the capability to fabricate high packing density films by the atom by atom transport growth mechanism at low substrate temperature [21].

\section{Experimental Technique}

Aluminum zinc oxide thin layers were prepared by DC sputtering under a base pressure of argon of 15 mTorr. The AZO target (from Cathey) with a purity of $99.998 \%$ and 3 inch diameter was used. The distance between the target and substrate was fixed at $11 \mathrm{~cm}$. For homogeneity of the films, periodic motion of $2 \mathrm{rpm}$ of the substrates was adopted. Thin films of AZO were deposited on a pre-cleaned glass substrate using UNIVEX 350 sputtering unit with de power model Turbo drive TD20 classic (Lybold) and rate thickness monitor model INFICON AOM-160. The structural characteristics of AZO thin films were investigated by X-ray diffraction pattern. Philips X-ray diffractometer model X Pert was used for the measurements which utilized monochromatic $\mathrm{CuK} \alpha=1.5406 \AA$ radiation operated at 40 kilovolt and $25 \mathrm{~mA}$. Reflectance $\mathrm{R}$ and transmittance $\mathrm{T}$ measurements at near-normal incidence in the spectral range 200-1000 nm were performed by using double beam spectrophotometer (JASCO model V-670 UV-VIS-NIR). The substrate temperature was kept at $25{ }^{\circ} \mathrm{C}$ during deposition.

\section{Theory and Calculations}

In order to obtain the optical energy gap $E_{o p}$, the following equation was used [22];

$$
(\alpha h v)^{b}=A\left(h v-E_{o p}\right)
$$

and the absorption coefficient $\alpha$ can be expressed as [23];

$$
\alpha=\frac{1}{d} \operatorname{Ln}\left(\frac{(1-R)^{2}}{T}\right)
$$

the correct value of transmittance $T$ is given by [24];

$$
T=\left(\frac{I_{f t}}{I_{g}}\right)\left(1-R_{g}\right)
$$

( $h v$ ) is the incident photon energy, $R$ is the reflectance, $R_{g}$ is the reflectance of glass substrate, $I_{f t}$ is the intensity of light passing through the film-glass system, $I_{g}$ is the intensity of the light passing through the reference glass and $d$ is the film thickness. The real value of the reflectance $\mathrm{R}$ is given by [25];

$$
R=\left[\left(\frac{I_{f r}}{I_{m}}\right) R_{m}\left(1+\left[1-R_{g}\right]^{2}\right)-T^{2} R_{g}\right.
$$

$I_{f r}$ is the intensity of light reflected from the sample, $I_{m}$ is the intensity of light reflected from the reference mirror.

The refractive index $n$ was calculated from the following equation [30]:

$$
\left.n=\frac{1+R}{1-R}+\left[\frac{4 R}{(R-1)^{2}}-k^{2}\right)\right]^{1 / 2}
$$

where $k=\alpha \lambda / 4 \pi$ is the absorption index, and $\lambda$ the is incident wavelength.

The band tails of the localized states can be estimated to a first approximation by plotting the absorption edge data in terms of an equation originally given by Urbach [26]. It has been reported that $h v$ holds over several decades for a glassy material and takes the formula [26]

$$
\alpha=\alpha_{o} e^{\frac{h v}{E_{u}}}
$$

Using DiDomenico dispersion relationship [27], the single oscillator energy $E_{o}$ and dispersion energy $E_{d}$ can be calculated using the following equation:

$$
\left(n^{2}-1\right)^{-1}=\frac{E_{o}}{E_{d}}-\frac{1}{E_{o} E_{d}}(h v)^{2}
$$

\section{Results and Discussion}

\subsection{Factors Affecting the Optical Gap}

Thin films of $\mathrm{Al}_{2} \mathrm{ZnO}_{4}$ with 100, 150, 200, 250, and 300 $\mathrm{nm}$ thick were deposited at the same preparation conditions on glass substrate at room temperature. Figure 1 depicts the changes of the transmittance $\mathrm{T}(\%)$ with the incident wavelength revealing that the intensity of the transmittance decreased with increasing the thickness of the film in the range of wavelength from $500 \mathrm{~nm}$ to $700 \mathrm{~nm}$ due to thickness effect [31].

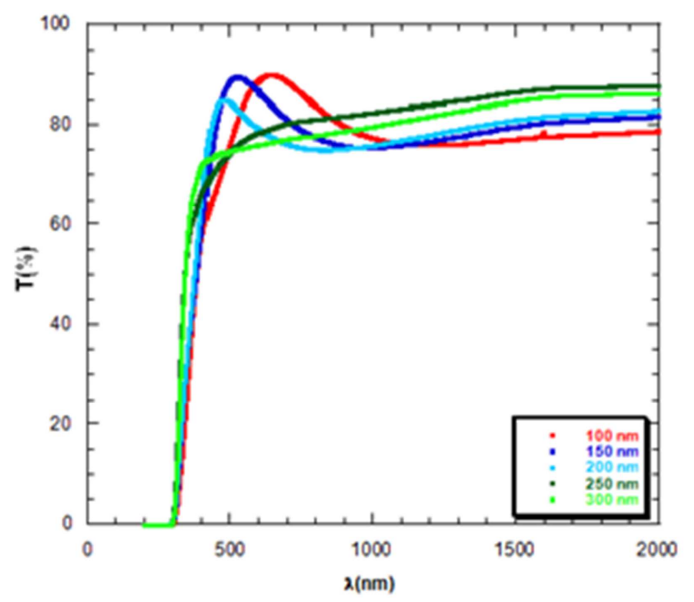

Fig. 1. Variations of transmittance $T$ with wavelength $\lambda$ for as-prepared $\mathrm{Al}_{2} \mathrm{ZnO}_{4}$ thin films of different thicknesses.

To obtain the optical energy gap, the plots $(\alpha h v)^{1 / 2}$ versus 
$h \vartheta$ to $(\alpha h v)^{1 / 2}=0.0$ were found to be the best fitting as shown in Fig. 2 indicating indirect optical energy gap. The calculated values of the optical energy gap were 3.53, 3.6, $3.62,3.65$, and $3.78 \mathrm{eV}$ for the thicknesses, 100, 150, 200, 250 , and $300 \mathrm{~nm}$ respectively revealing increasing the optical gap with thickness. This can be attributed to improvement in the crystals, in morphological changes of the films, in changes of atomic distances and grain size and structural defects in the films [32].

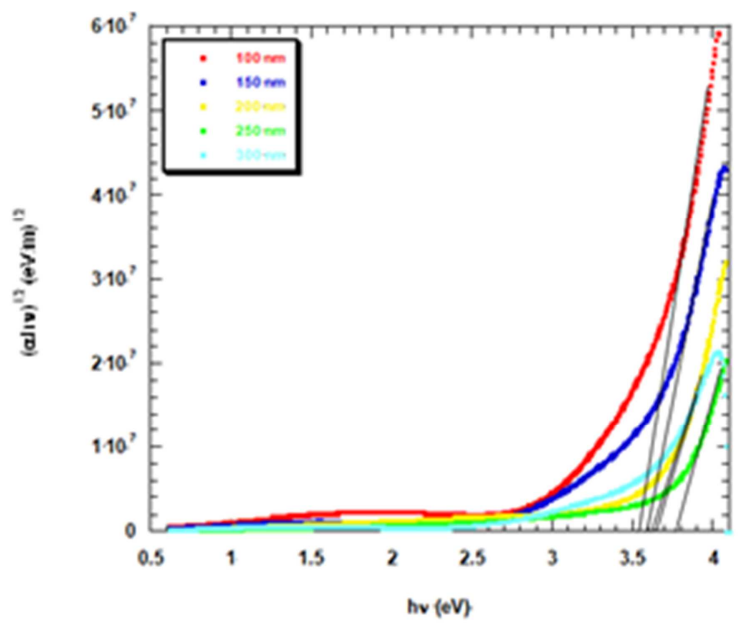

Fig. 2. Plots of $(\alpha h v)^{1 / 2} v$ s. hv for as-prepared $\mathrm{Al}_{2} \mathrm{ZnO}_{4}$ thin films of different thicknesses.

Four thin films of $\mathrm{Al}_{2} \mathrm{ZnO}_{4}$ of thickness $250 \mathrm{~nm}$ were prepared under the same condition, one of them was left asprepared, each one of the three films was annealed at certain temperature, 300,400 and $500^{\circ} \mathrm{C}$ for two hours. The variations of the transmittance $\mathrm{T}$ with wavelength $\lambda$ were plotted in Fig. 3 revealing decreasing of the transmittance with increasing the annealing temperature. The decrease of transmittance with increasing annealing temperature may interpreted as due to improvement of the degree of crystallinity of the films and/or increase of the grain size which is confirmed by the X-ray analysis [33]

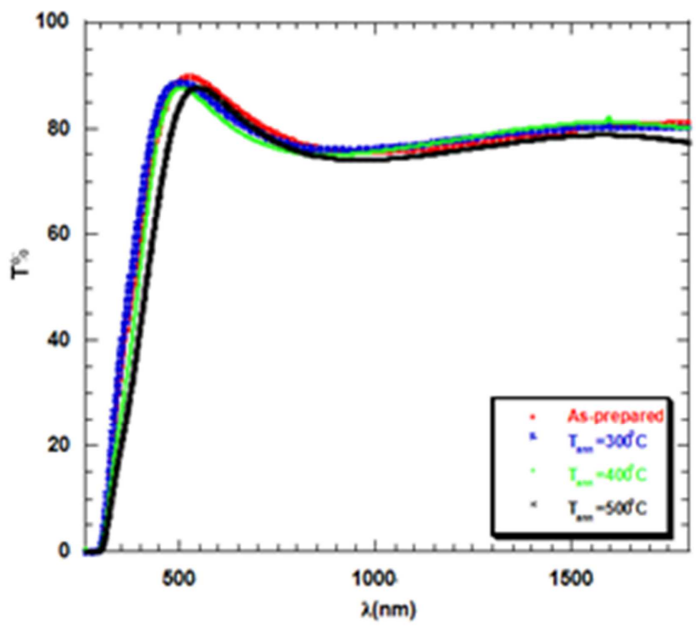

Fig. 3. Plots of $T$ vs. $\lambda$ for as-prepared and annealed AZOat different annealing temperatures ofthin films of $250 \mathrm{~nm}$.
The optical gap belonging to the annealed thin films at 300,400 and $500{ }^{\circ} \mathrm{C}$ were $3.7,3.75$, and $3.8 \mathrm{eV}$ respectively, indicating that increasing the optical energy gap with increasing the annealing temperatures ( Fig 4 representing the case of annealing temperature $300^{\circ} \mathrm{C}$, the rest were not plotted for avoiding overlapping). This may be explained as during the annealing process the films will have time for some atomic rearrangement to take place. So, some defects will be removed which reducing the density of dangling bonds, redistributing atomic distances and bond angles and the optical gap will then increases [34].

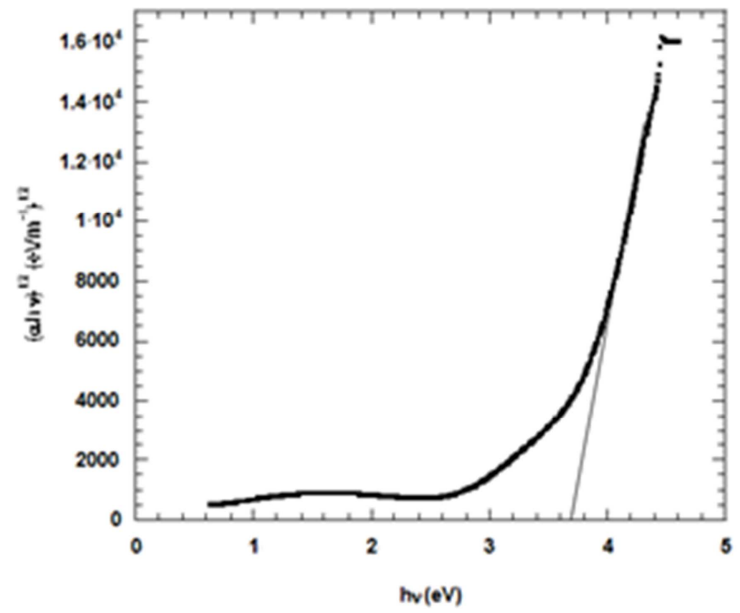

Fig. 4. Plots of $(\alpha h v)^{1 / 2}$ vs. hv for annealed $\mathrm{Al}_{2} \mathrm{ZnO}_{4}$ thin films of $250 \mathrm{~nm}$ thick at $300^{\circ} \mathrm{C}$

A set of as-prepared $\mathrm{Al}_{2} \mathrm{ZnO}_{4}$ thin film of $300 \mathrm{~nm}$ thick was prepared under different rate of flow of argon gas $(5,10$, $15,20,25$ and $30 \mathrm{sccm}$ ). Figure 5 shows the transmittance spectra of the prepared films indicating that at incident wavelength $500 \mathrm{~nm}$, the intensity of the transmittance was found to increase with increasing the flow rate of the gas which is in good agreement with those of the literature [35].

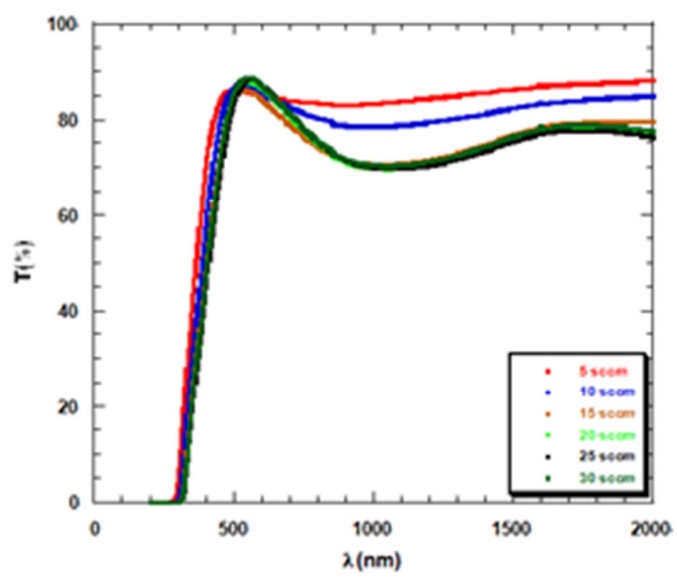

Fig. 5. Optical transmittance spectra of as-prepared AZO thin films prepared under different rate of flow of argon.

The allowed indirect optical energy gap decreased from $3.72 \mathrm{eV}$ down to $3.6 \mathrm{eV}$ with increasing the rate of flow from 5 to $15 \mathrm{sccm}$ and then became independent on the rate of 
flow where it has the same value $3.6 \mathrm{eV}$ for the rates 15,20 , 25, and $30 \mathrm{sccm}$ as shown in Fig. 6.

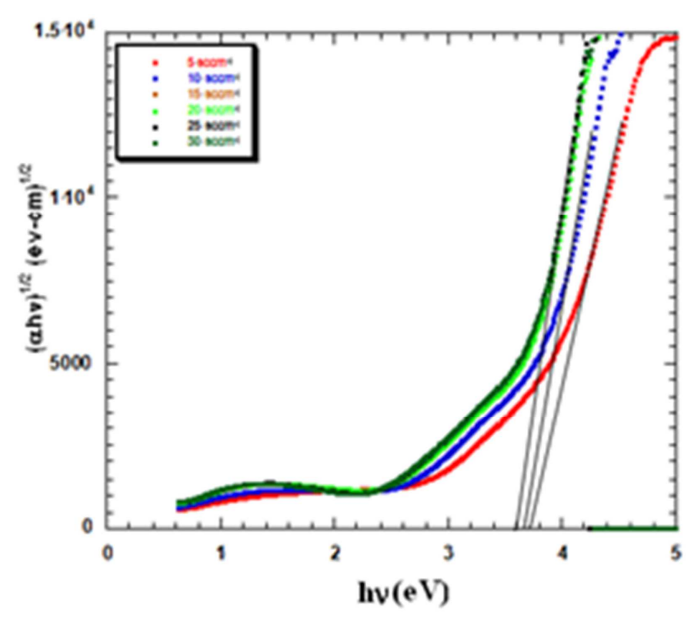

Fig. 6. Plots of $(\alpha h v)^{1 / 2} v$ s. hv for as-prepared AZO thin films prepared under different rate of flow of argon.

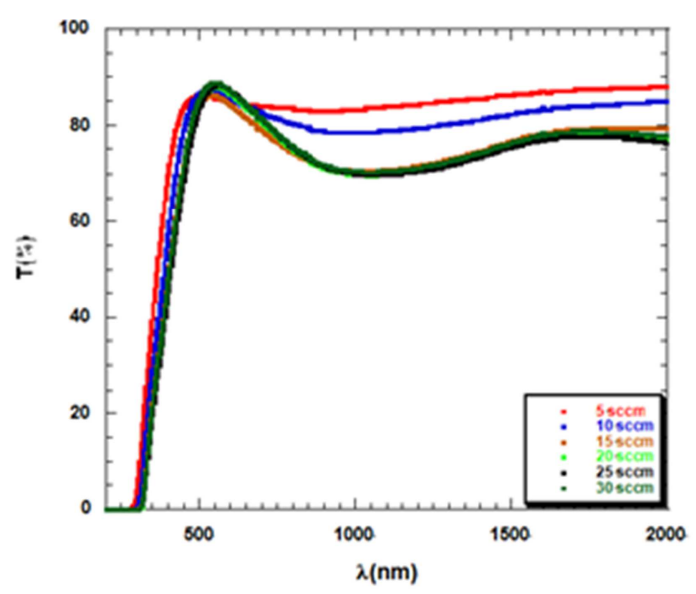

Fig. 7. Transmittance spectra of AZO thin films of $300 \mathrm{~nm}$ thick prepared under different rate of flow of argon and annealed at $500^{\circ} \mathrm{C}$.

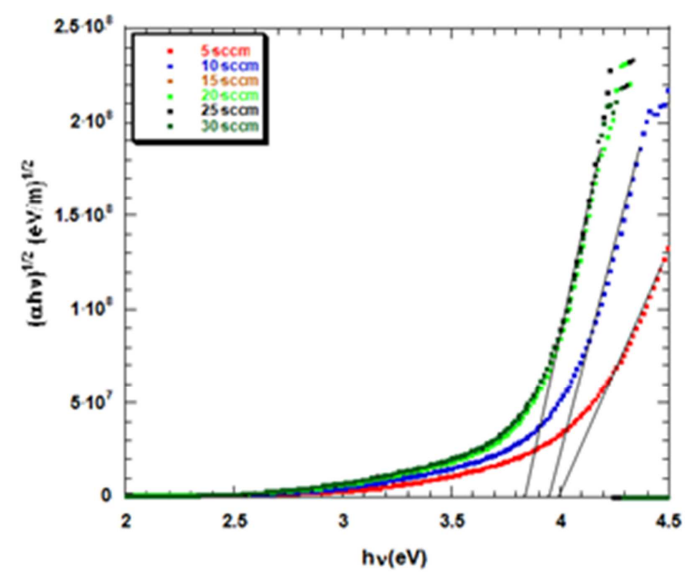

Fig. 8. Plots of $(\alpha h v)^{1 / 2} v$ s. hv for annealed AZO thin films of $300 \mathrm{~nm}$ thick prepared under different rate of flow of argon.

The last set of the thin films was annealed at $500^{\circ} \mathrm{C}$ for $2 \mathrm{hrs}$ and the optical measurements were carried out. Figure 8 reveals the transmittance spectra of the annealed $\mathrm{Al}_{2} \mathrm{ZnO}_{4}$ thin films prepared under different rate of flow of the gas. It is clear from Fig. 7 that the behavior of the transmittance of the annealed films confirmed the behavior of the asdeposited. The values of the indirect optical energy gap were estimated from Fig. 8 and found to be 3.99, 3.95, 3.83, 3.83, 3.83, and $3.83 \mathrm{eV}$ for the films prepared under the flow rate $5,10,15,20,25$ and $30 \mathrm{sccm}$ respectively. This result indicated that the indirect optical energy gap decreases with increasing the flow rate of argon up to $15 \mathrm{sccm}$ and then become independent on the flow rate.

Five thin films of $\mathrm{Al}_{2} \mathrm{ZnO}_{4}$ of the same thickness $300 \mathrm{~nm}$ and deposited under the same rate of gas flow $30 \mathrm{sccm}$, each film was deposited under certain argon pressure (5, 10, 20. 30,40 and $50 \mathrm{psi}$ ) at room temperature. The transmittance spectra showed that the transmittance decreased with increasing the pressure of the gas as seen in Fig. 9 which is in consistence with results of the literature [36-38]

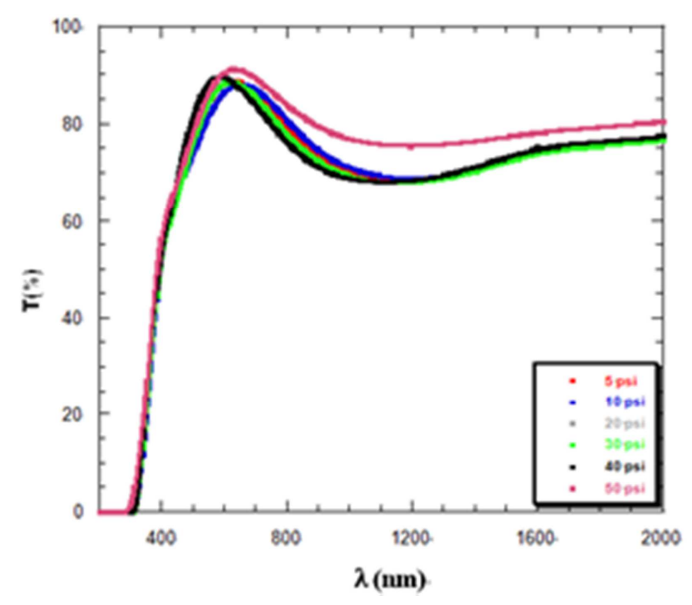

Fig. 9. Transmittance spectra of as-prepared AZO thin films deposited under different pressure of argon.

Figure 10 represents the plots of $(\alpha h v)^{1 / 2}$ versus $h v$ for the as-prepared $\mathrm{Al}_{2} \mathrm{ZnO}_{4}$ thin films prepared under different argon pressure. The obtained indirect allowed optical energy gap belonging to each argon pressure indicated that, it was independent on argon pressure, since, it had the same value $3.6 \mathrm{eV}$.

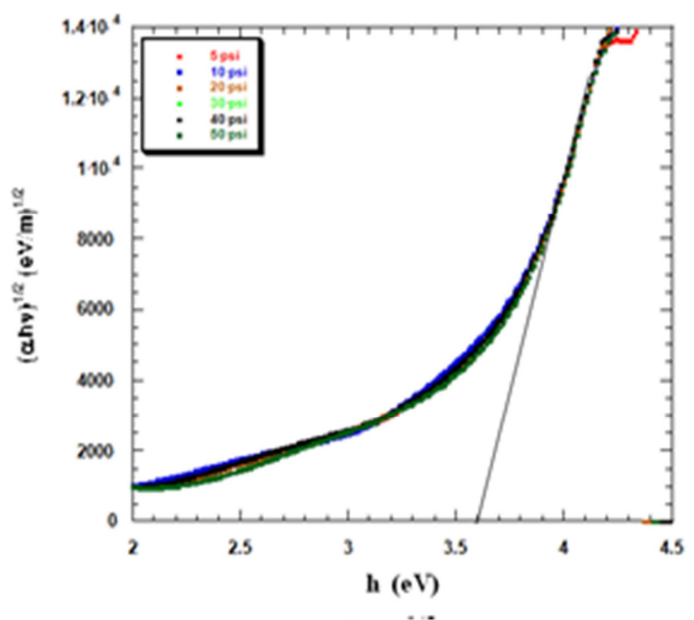

Fig. 10. Plots of $(\alpha h v)^{1 / 2}$ vs. hv for as-prepared AZO thin films prepared under different pressure of argon. 
The five thin films of $\mathrm{Al}_{2} \mathrm{ZnO}_{4}$ of the same thickness 300 $\mathrm{nm}$ were deposited under the same rate of gas flow $30 \mathrm{sccm}$ and each film was prepared under certain argon pressure (5, $10,20.30,40$ and $50 \mathrm{psi}$ ) and annealed at $500^{\circ} \mathrm{C}$ temperature for $2 \mathrm{hrs}$. Figure 11 depicts the transmittance spectra of these annealed films revealing that increasing argon pressure was accompanied with decreasing the transmittance. Besides, annealing the films did not affect the values of the transmittance compared with those belonging to the asprepared ones. The indirect optical energy gap of the annealed films estimated from Fig. 12 indicated that found to has the same value $3.5 \mathrm{eV}$.

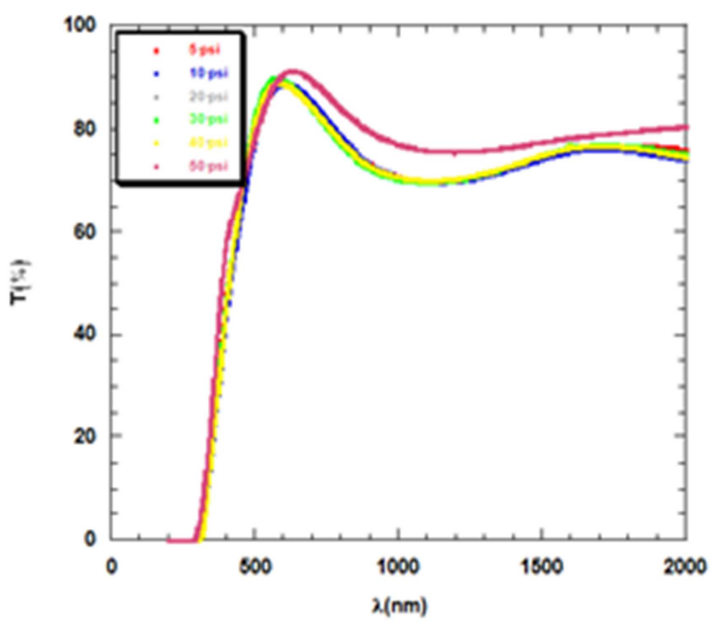

Fig. 11. Transmittance spectra for annealed $A Z O$ thin films at $500^{\circ} \mathrm{C}$ deposited under different pressure of argon.

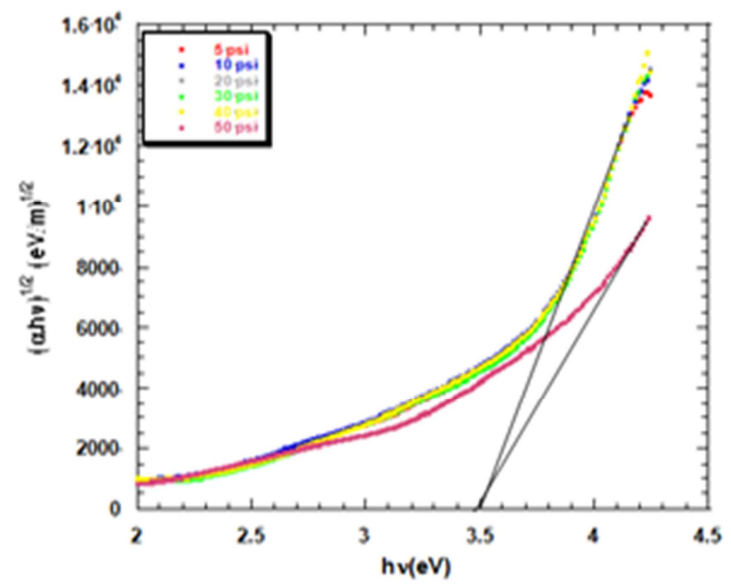

Fig. 12. Plots of $(\alpha h v)^{1 / 2}$ vs. hv for annealed $A Z O$ thin films at $500^{\circ} \mathrm{C}$ deposited under different pressure of argon.

From above, it can be said that thickness and annealing temperature affect the optical energy gap, whereas, changing the rate and value of pressure of argon have not affect the optical energy gap.

From above, it can be said that the optical energy gap is affected apparently with changing thickness annealing temperature, and rate of low specially the annealed films; on the other hand, changing the pressure of the gas has not affect the optical gap.

\subsection{Factors Affecting the Refractive Index}

The variations of the refractive index $n$ with wavelength was for thin films of different thicknesses were demonstrated in Fig13. It is obvious that the refractive index decreased monotonically with increasing the wavelength showing normal dispersion of the films of thicknesses 200 and $250 \mathrm{~nm}$ respectively. On the other hand, the films of thicknesses 100 , 150 and $300 \mathrm{~nm}$ showed a slight decrease with increasing the wavelength.

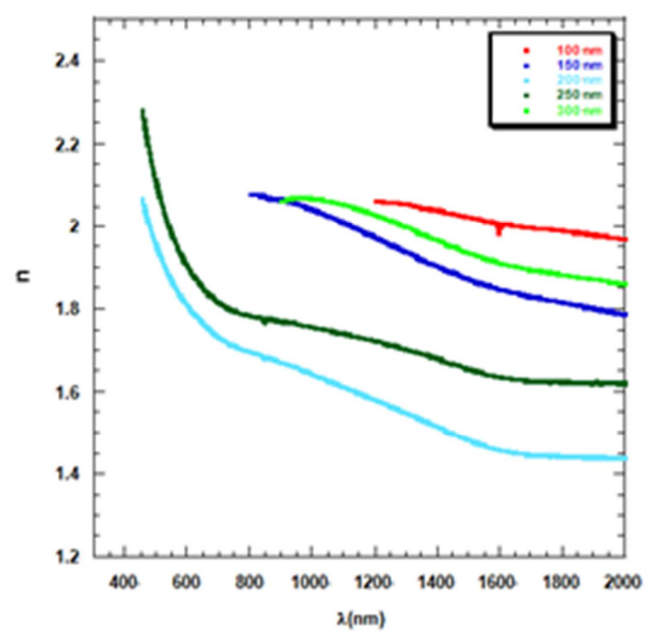

Fig. 13. Variations of the refractive index $n$ with wavelength for as-prepared AZO thin films of different thicknesses.

The changes of the refractive index $n$ with changing the incident wavelength for the thin films annealed at different temperatures were demonstrated in Fig. 14 where the refractive index decreased with increasing the wavelength in the range from 900 to $1600 \mathrm{~nm}$ revealing normal dispersion.

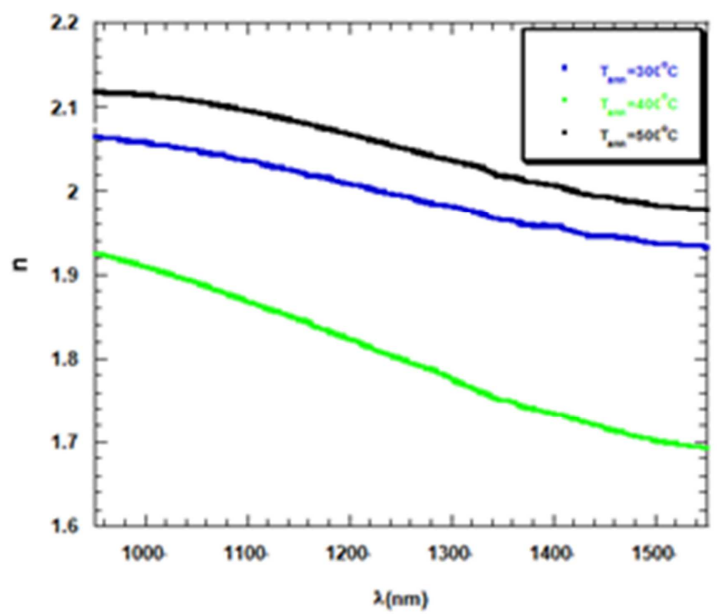

Fig. 14. Variations of the refractive index with wavelength for annealed $A Z O$ thin films of $250 \mathrm{~nm}$ thick at $300^{\circ} \mathrm{C}, 400^{\circ} \mathrm{C}$, and $500^{\circ} \mathrm{C}$

Regarding the results of the effect of changing both the thickness and annealing temperature on the refractive index, it was found that he refractive index behaves as normal dispersion with wavelength in spite of changing both the thickness and annealing temperature. 


\subsection{Factors Affecting Urbach Tails}

The width of the band tails of the localized states (Urbach tails) $E_{u}$ for the thin films of different thicknesses were estimated from the slop of the plots of $\operatorname{Ln}(\alpha)$ vs. $h v$ as shown in Fig. 15. The values calculated values of $E_{u}$ were found to be $0.64,0.55,0.55,0.58$ and $0.70 \mathrm{eV}$ for the thickness 100,150, 200, 250, and $300 \mathrm{~nm}$ respectively. The decreasing of the of the Urbach tails confirm those of the optical energy gap, where widening the optical gap has the same meaning of shrinking the width of the localized states.

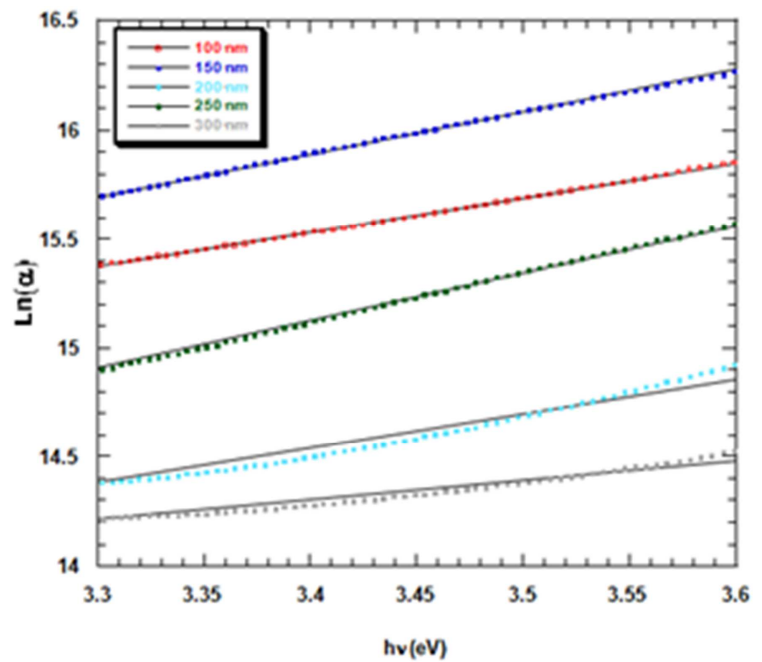

Fig. 15. Plots of Ln $\alpha$ vs. hv for as-prepared AZO thin films of different thicknesses.

The dependence of the width of the band tails of the localized states $\mathrm{E}_{\mathrm{u}}$ on annealing temperatures were calculated from the slope of the relations $\operatorname{Ln} \alpha-\mathrm{h} \nu$ as shown in Fig. 16. The values of $E_{u}$ were $0.60,0.62$, and $0.75 \mathrm{eV}$ for the annealed films at 300,400 , and $500^{\circ} \mathrm{C}$ respectively. It is clear that Urbach tails had the tendency of decreasing with increasing the annealing temperatures except for that annealed at $500^{\circ} \mathrm{C}$. These results are consistent with those belonging to optical energy gap of the annealed films.

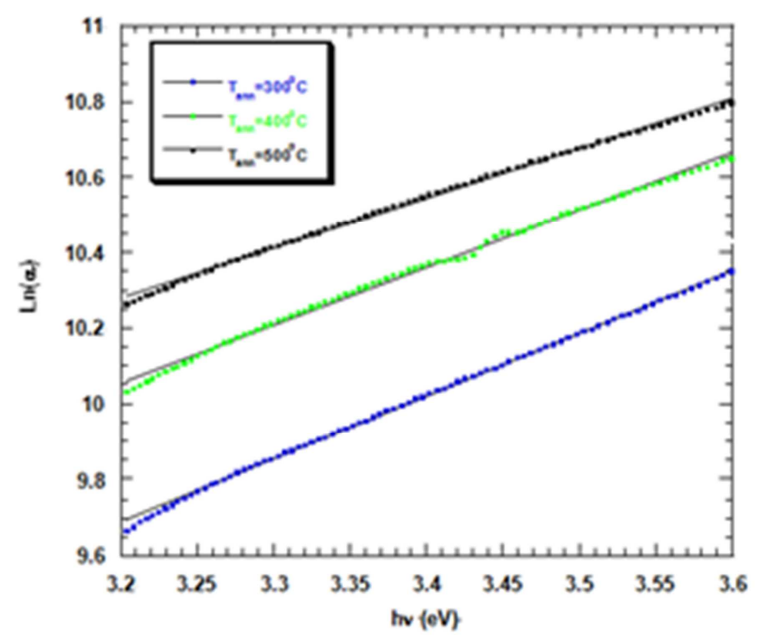

Fig. 16. Plots of Ln a vs. hv for annealed AZO thin films of $250 \mathrm{~nm}$ thick at different annealing temperatures.
Urbach tails of the thin films prepared under different rate of argon were calculated from Fig. 17 and found to be $0.63 \pm$ $0.02 \mathrm{eV}$ for the rate of flow from 5 up to $30 \mathrm{sccm}$ respectively, which agree with results of optical gap.

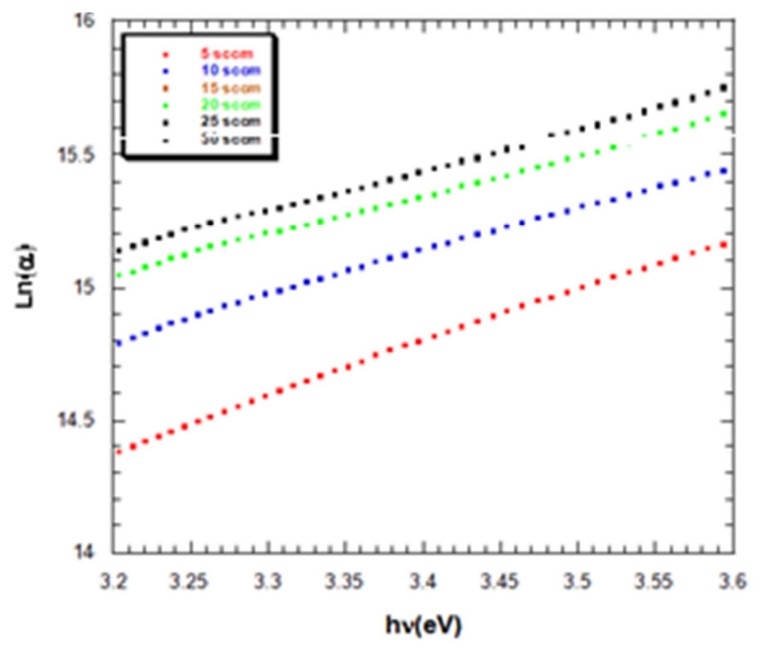

Fig. 17. Plots of $\mathrm{Ln}(\alpha)$ vs. hv for as-prepared thin films of $\mathrm{Al}_{2} \mathrm{ZnO}_{4}$ under different flow of argon.

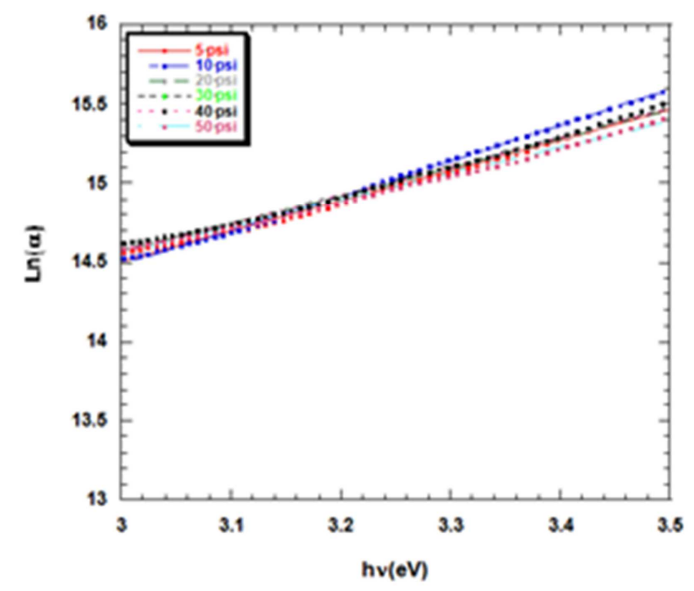

Fig. 18. Plots of Ln a vs. hv for AZO thin films deposited under different pressure of argon at room temperature.

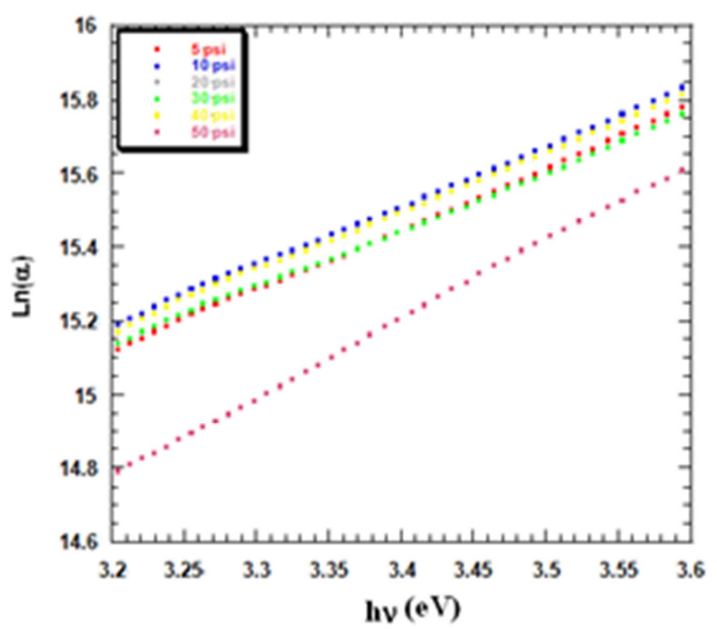

Fig. 19. Plots of Ln $\alpha$ vs. hv for annealed AZO thin films at $500^{\circ} \mathrm{C}$ deposited under different pressure of argon. 
Urbach tails from belonging to as-prepared $\mathrm{Al}_{2} \mathrm{ZnO}_{4}$ thin films deposited under different argon pressure were calculated from Fig. 18 which depict the relation $\operatorname{Ln}(\alpha)$ versus photon energy. The values of $E_{u}$ found to have the same value $0.53 \pm 0.02 \mathrm{eV}$ indicating also that the width of the bands of the localized states were independent on argon pressure. The calculated width of the band tails at the localized states of the annealed films at $500{ }^{\circ} \mathrm{C}$ for $2 \mathrm{hrs}$ found to has the same value $0.62 \pm 0.02 \mathrm{eV}$ except for the film prepared under argon pressure 50 psi as shown in Fig. 19.

The previous results indicated that Urbach tails increased with increasing both of thickness and annealing temperature, whereas both of rate and pressure of the gas has not affect the width of the bands of the localized states.

\subsection{Parameters Affecting the Single Oscillator and Dispersion Energy}

The single oscillator energy $E_{o}$ and dispersion energy $E_{d}$ were calculated for the films of different thicknesses and others annealed at different temperatures are recorded in table 1. As seen in table 1, the single oscillator energy increase with increasing both of thickness of the film and annealing temperature, whereas, the dispersion energy has a tendency of decreasing with both thickness and annealing temperature.

Table 1. Single oscillator energy, dispersion energy for thin films prepared under different conditions.

\begin{tabular}{llllll}
\hline $\begin{array}{l}\text { Thickness } \\
\mathbf{n m}\end{array}$ & $\mathbf{E}_{\mathbf{d}} \mathbf{e V}$ & $\mathbf{E}_{\mathbf{0}} \mathbf{e V}$ & $\begin{array}{l}\text { Annealing } \\
\text { temperature }{ }^{\mathbf{0}} \mathbf{C}\end{array}$ & $\mathbf{E}_{\mathbf{d}} \mathbf{e V}$ & $\mathbf{E}_{\mathbf{0}} \mathbf{e V}$ \\
\hline 100 & 2.70 & 0.87 & 300 & 3.32 & 2.37 \\
150 & 2.93 & 0.92 & 400 & 3.01 & 2.42 \\
200 & 3.23 & 1.29 & 500 & 3.11 & 2.74 \\
250 & 3.47 & 1.42 & & & \\
300 & 3.64 & 1.41 & & & \\
\hline
\end{tabular}

\section{Conclusion}

The above results reveal that the optical energy gap increases with both the film thickness and the annealing temperature, whereas both the rate and pressure of the gas has not affect the optical gap. Our results showed that the refractive index has normal dispersion in case of changing both the thickness of the films and annealing temperature. Urbach tails found to confirm the optical gap energy results. Single oscillator energy found to increase with thickness and annealing temperature. Dispersion energy has a tendency to decrease with both of thickness and annealing temperature.

\section{References}

[1] Jeong Soo, and Kyung Hwan Kim, Transaction on electrical and electronic materials 2(2) (2011) 76-79.

[2] B. Szyszka, Thin Solid Films 351 (1999) 164.

[3] O. Kluth, B. Rech, L. Houben, S. Wagner, A. Loffi, H. W. Schock, Thin Solid Films, 352 (1999) 247.
[4] M. J. Alam, D. C. Cameron, J. Vac. Sci. Technol. A 19(4) (2001) 1642.

[5] M. J. Alam, D. C. Cameron, Surf. Coat. Technol 142-144 (2001) 776 .

[6] P. Nunes, E. Fortunato, P. Tonello, F. Braz Fernandez, P. Vilarinho, R. Martins, Vacuum 64 (2002) 281.

[7] T. Minami, S. Susuki, T. Miyata, Thin Solid Films 398-399 (2001) 53 .

[8] M. Bertolotti, M. V. Laschena, M. Rossi, A. Ferrari, L. S. Qian, F. Quaranta, A. Valentini, J. Mater. Res. 5 ((9) (1990) 1929.

[9] K. -S. Weibenrieder, J. MuEller, Thin Solid Films 300 (1997) 3.

[10] J. L. Deschanvres, B. Bochu, J. C. Joubert, J. Phys. 4(3) (1993) 485.

[11] J. Yoo, J. Lee, S. Kim, K. Yoon, I. Jun Park, S. K. Dhungel, B. Karunagaran, D. Mangalaraj, Junsin Yi, Thin Solid Films 480481 (2005) 213-217.

[12] J.-H. Lee, B.-O. Park, Mater. Sci. Eng. B 106 (2004) 242.

[13] S. Major, S. Kumar, M. Bhatnagar, K. L. Chopra, Appl. Hys. Lett. 49 (1986) 394.

[14] S. H. Mohamed, H. M. Ali, H. A. Mohamed, A. M. Salim, Eur. Phys. J. Appl. Phys. 31 (2005) 95-99.

[15] A. E. Jimenez-Gonzalez, J. A. S. Urueta, R. Suarez-Parra, J. Cryst. Growth 192 (1998) 430-43.

[16] Y. Cao, L. Miao, S. Tanemura, M. Tanemura, Y. Kuno, Y. Hayashi, and Y. Mori, J. Appl. Phys. 45 (2006) 1623-1628.

[17] W. W. Wenas, A. Yamada, M. Konagai, K. Takahashi, Jpn. J. Appl. Phys. 30 (1991) L441.

[18] T. Tsuchiya, T. Emoto, T. Sei, J. Non-Cryst. Solids 178 (1994) 327.

[19] M. de la, L Olvera, A. Maldonado, R. Asomoza, M. Mele ndez-Lira, Sol. Energy mater, Sol. Cells 71 (2002) 61.

[20] J. A. Anna Selvan, H. Keppner, A. Shah, mater. Res. Soc. Symp. Proc. 426 (1996) 497.

[21] J. C. Hsu, C. C. Lee, Appl. Opt/ 37 (1998) 1171.

[22] U. Pal, D. Samanta, S. Ghori, and A. K. Chaudhuri, J. Appl. Phys. 74 (10) (1993) 6368.

[23] H. M. Ali, Phys. Status Solidi A 202, (2005) 2742.

[24] M.M. El-Nahass, J. Mater. Sci. 27 (1992) 6592.

[25] A.M. Bakry, A.H. El-Naggar, Thin Solid Films 360 (2000) 293.

[26] F. Urbach, Phys. Rev. 92 (1953) 1324.

[27] S. H. Wemple and DiDomenco. Rev. B7 (1973) 3767.

[28] T. Tsuji, and M. Hirohashi, Appl. Surf. Sci. 157 (200) 47.

[29] J. Y. Seto, J. Appl. Phys 26 (1975) 5247.

[30] M. D. Barankin, E. Gonzalez II, A. M. Ladwing, R. F. Hicks, Solar Energy Materials \& Solar Cells 91 (2007) 924-930. 
[31] S.H. Jeong, J.W. Lee, S.B. Lee, J.H. Boo, Thin Solid Films 435 (2003) 78-82.

[32] Yunus Akaltun, M. Ali Yıldırım, Aytunç Ateş Muhammet Y1ld, Optics Communications 284 (2011) 2307-2311.

[33] M. M. Abd El-Raheem, H. M. Ali, N. M. El-Husainy, Journal of optoelectronics and advanced materials 11 (2009) 813-819.

[34] B. A. Mansour, H. Shaban, S. A. Gad, Y. A. El-Gendy, A. M.Salem, Journal of Ovonic Research,Vol. 6, No.1,( 2010), p. $13-22$.

[35] Chin-Chiuan Kuo, Chi-Chang Liu, Shao-Chih He, Jing-Tang
Chang, and Ju-Liang He, Journal of nanomaterials, volume 2012, article ID 562701, 8 pages.

[36] J. Yoo, J. Lee, S. Kim, K. Yoon, I. Jun Park, S. K. Dhungel, B. Karunagaran, D. Mangalaraj, Junsin Yi, Thin Solid Films 480481 (2005) 213-217.

[37] Yasuhiro Igasaki, Hirokazu Kanma, Applied Surface Science 169-170 (2001) 508-511.

[38] V. Assuncao , E. Fortunato *, A. Marques, H. Aguas , I. Ferreira, M.E.V. Costa, R. Martins, Thin Solid Films 427 (2003) 401-405. 